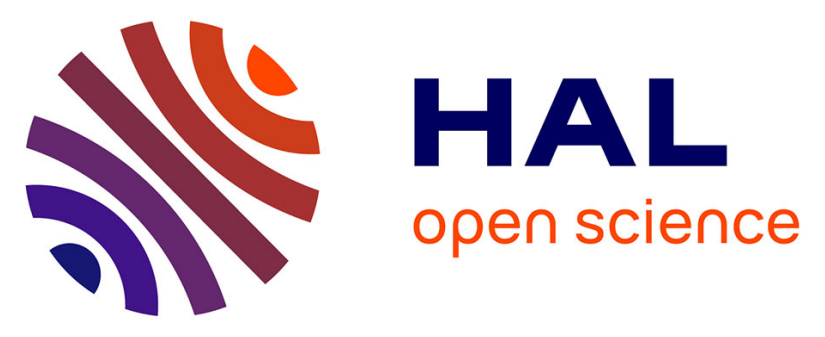

\title{
The MAELIA multi-agent platform for integrated analysis of interactions between agricultural land-use and low-water management strategies
}

Benoit Gaudou, Christophe Sibertin-Blanc, Olivier Therond, Fredéric Amblard, Yves Auda, Jean-Paul Arcangeli, Maud Balestrat, Marie-Hélène Charron-Moirez, Etienne Gondet, Yi Hong, et al.

\section{To cite this version:}

Benoit Gaudou, Christophe Sibertin-Blanc, Olivier Therond, Fredéric Amblard, Yves Auda, et al.. The MAELIA multi-agent platform for integrated analysis of interactions between agricultural landuse and low-water management strategies. International Workshop on Multi-Agent-Based Simulation MABS 2013, May 2013, Saint-Paul (MN), United States. pp. 85-110, 10.1007/978-3-642-54783-6_6 . hal-01144166

\author{
HAL Id: hal-01144166 \\ https://hal.science/hal-01144166
}

Submitted on 27 Apr 2015

HAL is a multi-disciplinary open access archive for the deposit and dissemination of scientific research documents, whether they are published or not. The documents may come from teaching and research institutions in France or abroad, or from public or private research centers.
L'archive ouverte pluridisciplinaire HAL, est destinée au dépôt et à la diffusion de documents scientifiques de niveau recherche, publiés ou non, émanant des établissements d'enseignement et de recherche français ou étrangers, des laboratoires publics ou privés. 


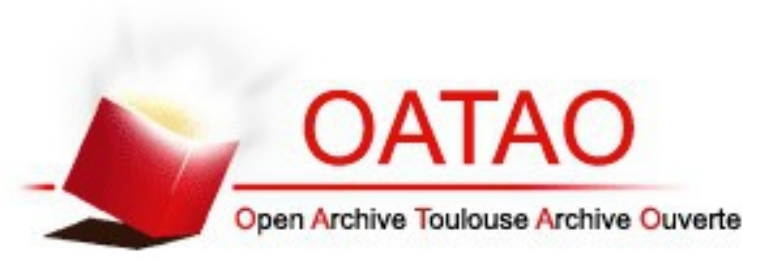

\section{Open Archive TOULOUSE Archive Ouverte (OATAO)}

OATAO is an open access repository that collects the work of Toulouse researchers and makes it freely available over the web where possible.

This is an author-deposited version published in : http://oatao.univ-toulouse.fr/ Eprints ID : 12540

To link to this article : DOI :10.1007/978-3-642-54783-6_6 URL : http://dx.doi.org/10.1007/978-3-642-54783-6 6

To cite this version : Gaudou, Benoit and Sibertin-Blanc, Christophe and Therond, Olivier and Amblard, Fredéric and Auda, Yves and Arcangeli, Jean-Paul and Balestrat, Maud and Charron-Moirez, MarieHélène and Gondet, Etienne and Hong, Yi and Lardy, Romain and Louail, Thomas and Mayor, Eunate and Panzoli, David and Sauvage, Sabine and Sanchez-Pérez, José-Miguel and Taillandier, Patrick and Nguyen, Van Bai and Vavasseur, Maroussia and Mazzega, Pierre $\underline{T h e}$ MAELIA multi-agent platform for integrated assessment of low-water management issues. (2014) In: International Workshop on Multi-AgentBased Simulation - MABS 2013, 6 May 2013 - 7 May 2013

(Minnesota, United States).

Any correspondance concerning this service should be sent to the repository administrator: staff-oatao@,listes-diff.inp-toulouse.fr 


\title{
The MAELIA Multi-Agent Platform for Integrated Analysis of Interactions Between Agricultural Land-Use and Low-Water Management Strategies
}

\author{
Benoit Gaudou ${ }^{1(\bowtie)}$, Christophe Sibertin-Blanc ${ }^{1(\bowtie)}$, \\ Olivier Therond ${ }^{2(凶)}$, Frédéric Amblard ${ }^{1}$, Yves Auda ${ }^{3}$, \\ Jean-Paul Arcangeli ${ }^{1}$, Maud Balestrat ${ }^{2,3}$, \\ Marie-Hélène Charron-Moirez ${ }^{2}$, Etienne Gondet ${ }^{3}$, Yi Hong ${ }^{1,4,5}$, \\ Romain Lardy ${ }^{2}$, Thomas Louail ${ }^{1}$, Eunate Mayor ${ }^{1}$, David Panzoli ${ }^{6}$, \\ Sabine Sauvage ${ }^{4,5}$, José-Miguel Sánchez-Pérez ${ }^{4,5}$, \\ Patrick Taillandier ${ }^{7}$, Nguyen Van $\mathrm{Bai}^{3}$, Maroussia Vavasseur ${ }^{1,2}$, \\ and Pierre Mazzega ${ }^{3,8}$ \\ ${ }^{1}$ UMR 5505 IRIT, CNRS, University of Toulouse, Toulouse, France \\ \{benoit.gaudou, \\ Christophe.Sibertin-Blanc\}@ut-capitole.fr \\ ${ }^{2}$ UMR 1248 AGIR, INRA-INPT, Castanet-Tolosan, France \\ olivier. therond@toulouse.inra.fr \\ 3 UMR 5563 GET, IRD-UPS-CNRS-CNES, OMP, Toulouse, France \\ ${ }^{4}$ INP, UPS; EcoLab, Université de Toulouse, 31326 Castanet Tolosan, France \\ ${ }^{5}$ CNRS, EcoLab, 31062 Toulouse, France \\ ${ }^{6}$ Centre Universitaire Jean-François Champollion, Albi, France \\ 7 UMR 6266 IDEES, CNRS, University of Rouen, Rouen, France \\ 8 Joint Mixt Laboratory OCE, UnB/IRD, LAGEQ, Universidade de Brasília, \\ Brasília, Brazil
}

\begin{abstract}
The MAELIA project is developing an agent-based modeling and simulation platform to study the environmental, economic and social impacts of various regulations regarding water use and water management in combination with climate change. It is applied to the case of the French Adour-Garonne Basin, which is the most concerned in France by water scarcity during the low-water period. An integrated approach has been chosen to model this social-ecological system: the model combines spatiotemporal models of ecologic (e.g. rainfall and temperature changes, water flow and plant growth) and socio-economic (e.g. farmer decision-making process, management of low-water flow, demography, land use and land cover changes) processes and sub-models of cognitive sharing among agents (e.g. weather forecast, normative constraints on behaviors).
\end{abstract}

Keywords: Social-ecological systems · Water management · Integrated assessment and modeling - Agent-based model

Benoit Gaudou, Christophe Sibertin-Blanc, Olivier Therond-These authors contributed equally to this work. 


\section{Introduction}

Environmental and resource management problems are typically complex. They concern many actors with diverse and contrasting interests and objectives. They emerge into social-ecological systems (SES, i.e. coupled human-environment systems) in which four first-level core subsystems interact: two ecological ones (i) resource systems (e.g. water systems); (ii) resource units (e.g. water volume and flow) and two social ones (iii) governance systems (e.g., organizations that manage water resources and systems); and (iv) users (e.g. individuals and collectives who use water) [8]. Interactions within and between these subsystems give rises to emergent structures and functions at sub and whole system levels [11].

During the last decades, integrated assessment has been playing an increasing role to address sustainability issues and the associated environmental and resources management problems [9]. Integrated Assessment and Modelling (IAM) purpose is to assemble data and knowledge from a wide range of scientific disciplines and put them into a "policy oriented context" in order to analyse complex system responses to changes and design sound sustainable management and development strategies [9]. It is a model-based approach that combines representations of different multi-level subsystems into a cohesive framework [10]. The agent-based modelling and simulation approach is recognised as especially suited to deal with the understanding of SESs since it allows to represent interactions within and between the social and the ecological systems [1]. IAM approaches are frequently used for assessing scenarios. These "scenario exercises" allow decision-makers to explore and evaluate the potential consequences of different policy options or management strategies, in the context of socio-economic (e.g. demography, market, political framework), environmental (e.g. climate change) and technological (e.g. new cropping systems) changes [16].

Water resource management is typical of environmental management problems emerging from complex social-ecological systems. It deeply interacts with land use management and with global environmental and societal changes [5]. IAM is a way to model and simulate interacting ecological and socio-economic processes occurring at the catchment level in order to identify water and land management strategies allowing balancing water demands with supplies [4]. Water scarcity is a serious problem in the Adour-Garonne Basin (AGB, South-West France) with an annual deficit between demands and resources of 250 million $\mathrm{m}^{3}$. In this basin, irrigated agriculture is the main consumer of water (about $80 \%$ ) during the low-water period. Despite important structural management arrangements being implemented to address this deficit, water flow rates under the compulsory thresholds set for the proper functioning of aquatic ecosystems are regularly found. To face such "water crises", the local government states irrigation withdrawal restrictions that may reduce crop yields and accordingly farmer' incomes. Due to implementation of the European Water Framework Directive (WFD) the French government is redesigning its water scarcity policy taking into account the expected effect of climate change (higher temperature and lower rainfall in the summer).

The MAELIA project aims at developing a simulation platform to assess the environmental, economic and social impacts of various management strategies and 
policies regarding the management and the uses of water resources while accounting for climate changes. This computational multi-agent platform is developed to provide information usable by institutions in charge of designing and implementing sustainable management strategies of water resources at watershed levels in the AGB.

This paper presents the IAM MAELIA platform. The second section sketches the water management problem to be handled with the platform. The third section presents the modelling conceptual and methodological framework and the software platform used to develop MAELIA. The fourth section describes the MAELIA model, i.e. how entities and processes are modelled within the platform. We conclude by highlighting the challenge regarding calibration of such an IAM platform.

\section{The French Water Scarcity Management Issue}

In the AGB, so far, French state services grant water withdrawal authorizations to farmers according to their requests without information to accurately estimate the consistency between the sum of farmers' requests and the available water resources in each watershed. As a consequence, very regularly local State services have to manage "water crises" i.e. to face with the risk that water flow rates pass under the compulsory water flow rates at given hydrological monitoring points. To avoid such illegal hydrological situations, when possible they release water from dams and if necessary they issue drought decrees that state irrigation withdrawal limitations or prohibitions. These restrictions are set up for specific locations (some districts) and durations (at least one week) and may cause significant crop yield reductions.

To overcome the recurrent water quantity management problems, the French Law on the Water and Aquatic Ecosystems (LWAE - French implementation of the WFD) institutes a new regulation of agricultural water withdrawals [3]. One of the objectives of this law is to prevent water crises, which should in average occur only one year in five in a given watershed. Its implementation, still in progress, led regional State services to determine for each elementary watershed the water volume that remains available for agriculture the driest hydrological year in a statistical 5-year period. This annual volume should be distributed between irrigated farmers of each Water Distribution Area (a coherent assembly of elementary watersheds) by a specific local organism representative of irrigated farmers. In many watersheds of the AGB, this volume is (much) under the water volume currently withdrawn by farmers during normal or even dry climatic years. This reduction of available water volumes for irrigation gives rise to vehement protests of farmers. They argue that such a water management leads to restrict agricultural water withdrawals, four years in five, much more than necessary to ensure a safe water flow in rivers. Farmers claim that the only way to manage water in river basins in order to ensure the viability of both existing farming systems and aquatic ecosystems is to manage the resource according to the actual water flow.

To identify strengths and weaknesses of different water management options, the MAELIA platform will assess the four following scenarios: 
- Management by rate of flow (as asked by farmers): the daily management of lowwaters relies on water releases and drought decrees;

- Management by pluri-annual volume (the management option that the French water law is trying to implement): farmers are assigned a predetermined annual volume that they may use at their discretion;

- Management by annual volume (a refined alternative of the previous solution): the volume for the next low-water period is defined during the spring according to the state of water resources and weather forecast;

- Management by weekly or monthly volume (a more refined option): available volumes for the next period are regularly defined and published according to the current water resources state and weather forecasts.

MAELIA will run simulations of these scenarios in combination with various climate change forecasts over the future twenty years. The assessment relies on environmental, economic and social outcomes such as water flow at the regulatory monitoring points, water releases, water drought decrees frequency and intensity (water crises), crop acreages, crop yields or farmer incomes.

\section{Modeling Methodology and Tools}

The MAELIA IAM platform development requires integration of knowledge from various disciplines (agronomics, hydrology...) and activities (farming, administering...). To this end, MAELIA developed a (conceptual) meta-model enabling collection and integration of heterogeneous knowledge into a coherent description of the system under consideration. This meta-model supports the elaboration of a conceptual model of the investigated SES shared by all participants of the modelling process [13].

\subsection{The MAELIA Meta-model}

The meta-model, shown in Fig. 1, considers SESs as double-faced: (i) a structure that constitutes the observable matter of the system where phenomena take place and (ii) a dynamics that produces the behavior of the system and generates the phenomena of interest. In addition, a SES suffers influences from its environment.

The structure of a system is composed of entities and relationships between them. Entities are lasting elements that may appear or disappear over time and experience changes. Each entity is characterized by attributes, whose values constitute its state, and is endowed with operations that process attribute values. We distinguish three types of entities, actors, material resources and cognitive resources:

- Actors are human agents that perform activities, be they an individual, a population of similar individuals or a group such as an organization, association or committee.

- Material resources are physical objects, spatially and temporally distributed such as a water body, a field plot or a dam.

- Cognitive resources stay in the minds of human beings; they are information, believes or expectations about facts, procedures or values that actors use or consider 


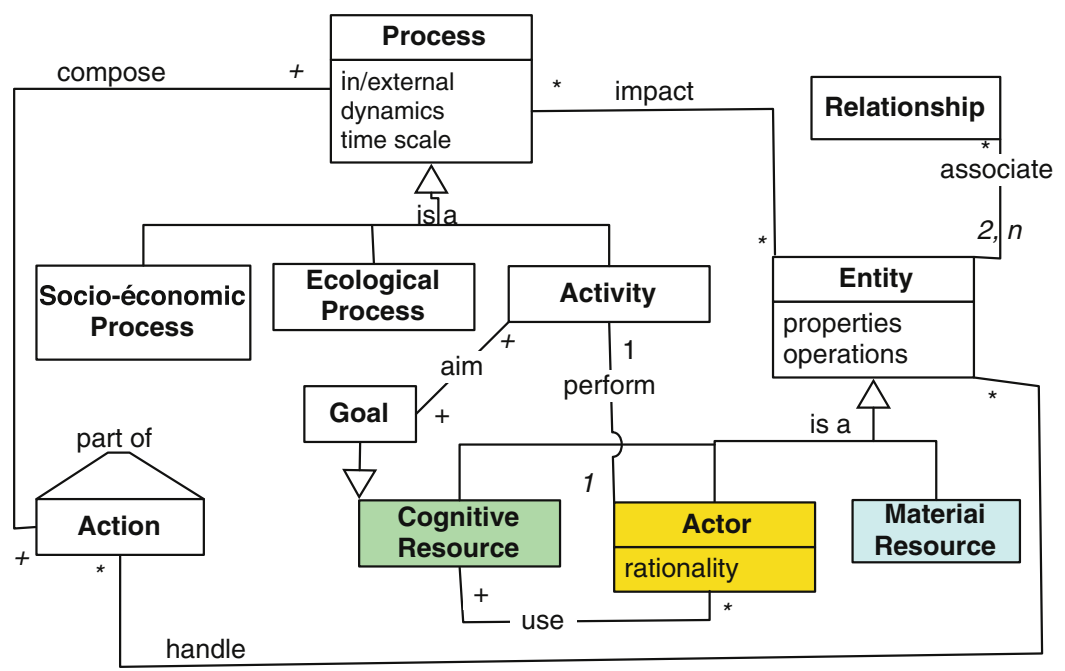

Fig. 1. The MAELIA meta-model represented as a UML Class diagram

in the performance of activities they undertake, in planning and decision making or in the formation of goals.

A relationship associates two entities due either to their very nature (e.g. each field plot has a soil type) or as a state of affairs resulting from a contingent action (e.g. a farmer owns a plot after he has bought it). At any moment, the structure of the system model is defined as the collection of its entities and necessary relationships, while its state is defined as the states of entities with their contingent relationships. The structure of the model is graphically represented as an Actor-Resource Diagram (ARD), or a set of such diagrams, that use the UML class diagram notation (see Fig. 2).

The dynamics of a system is the set of processes that modify the structure and the state of the system and so generate the phenomena of interest. Each execution of a process impacts some entities by changing their state or by creating or destroying entity instances or links. We distinguish three categories of processes, (human) activities, socio-economic processes and ecological processes:

- An Activity is a process executed by an actor intending to achieve some goals (e.g. to irrigate a field plot; to issue a drought decree); actors are endowed with a rationality to solve problems about the performance of enabled activities, since most activities may be carried out in several ways and conflicts between activities can occur.

- An Ecological process corresponds to the enactment of biophysical laws that determine the evolution of material resources (e.g. runoff of water; growth of crop, evapotranspiration...). 


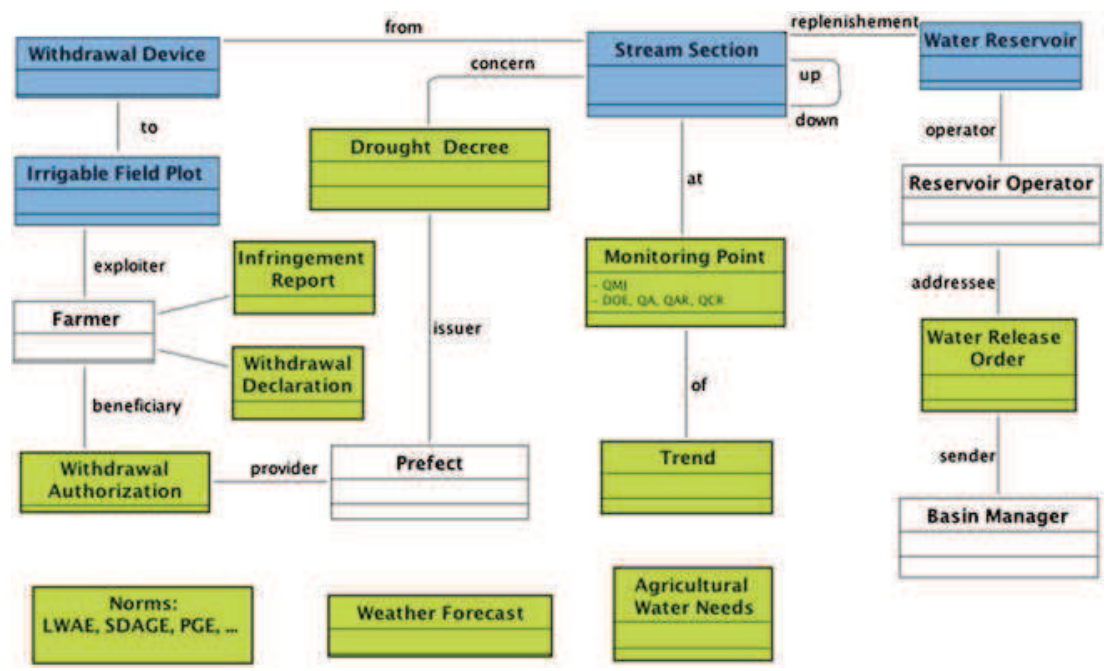

Fig. 2. An excerpt of the Actors-Resources Diagram of MAELIA regarding regulation issues. Actors, material resources and cognitive resources are figured as white, blue and green boxes respectively (Color figure online).

- A Socio-economic process generates phenomena resulting from the humans' economic and social activities (e.g. price evolution, urbanization). Only the effects of a socio-economic process are considered, without regarding how and by whom these effects are produced.

A process is broken down into actions. It is described by systems of equations, automata, algorithms or systems of (event-condition-action) rules, according to the most appropriate way. The dynamics of a process describes the scheduling of actions executions. Each process has its own spatial, functional and temporal resolutions that determine how it must be dealt with by the simulation engine.

The processes interact through entities. Indeed, at each time step of a system run, the current state determines the processes that are enabled and the processing they have to do, and the execution of these processes determines the system state at the next step. In an opposite view, entities are glued together by processes that make their evolution interdependent. Figure 3 is an Interaction diagram that shows the interweaving of processes and entities.

The behaviour of a system is influenced by its environment, so a simulation model must include the impact of the environment on the system. The environment of the system is defined as the set of processes that influence the system behaviour while their dynamics do not depend on its state or evolution. These processes are qualified as external. As examples, at the local level, the rain and the international price of corn are typically produced by external processes. Like any process, they impact the system through entities that are, from this fact, qualified as interface entities. Thus, an external process is described by a (spatio-) temporal series including, for each time step of a simulation, the new values (or the variations) of the state of interface entities. 


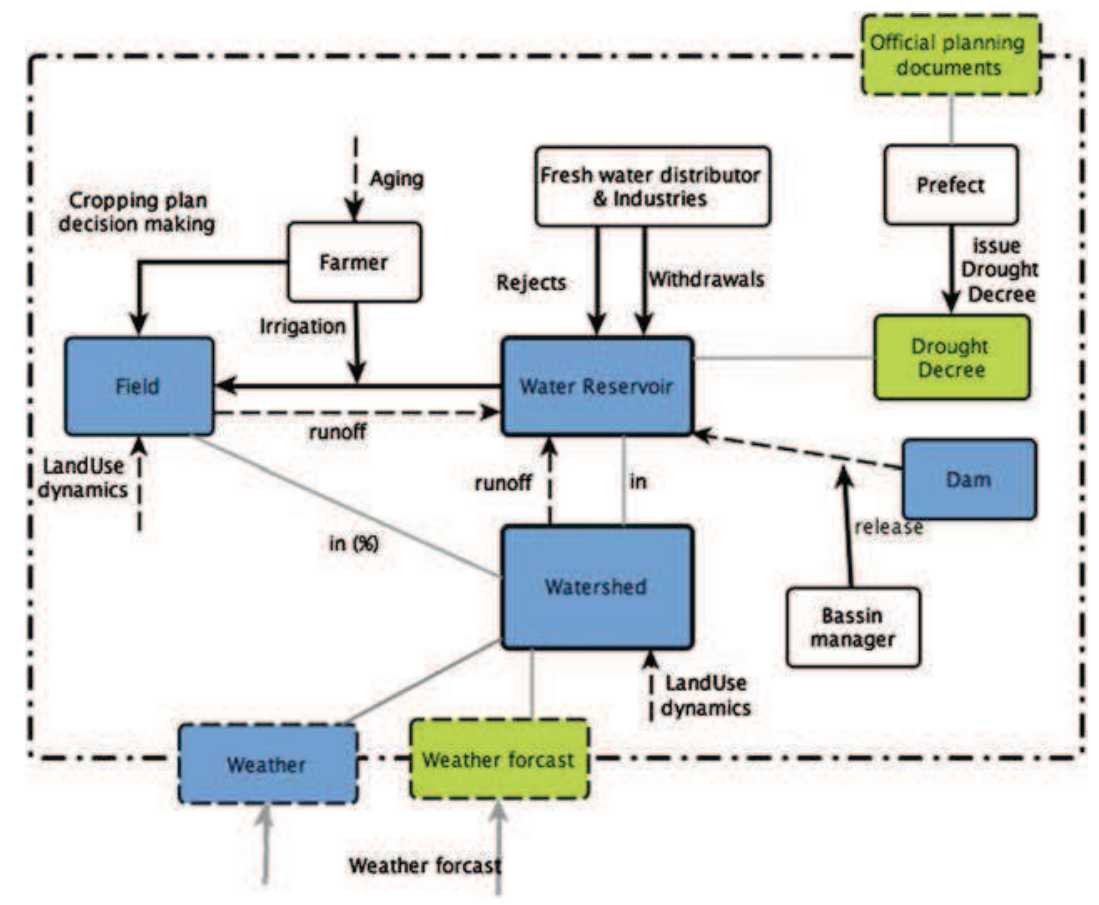

Fig. 3. An excerpt of one Interaction Diagram of the MAELIA model intended to outline interactions between processes and entities. Actors, material resources and cognitive resources are figured as white, blue and green boxes respectively. Thin lines between boxes are essential associations between entities. Ecological and socio-economic processes are represented as dashed arrows connected to the main entities they use or modify. Activities are represented as arrows from the performer actor to the main impacted entities. The dashed border points out interface entities and external processes (Color figure online)

\subsection{The Modeling Process}

Such a meta-model assists modellers in defining and designing the components of the model to be implemented, and thus the outcomes to be delivered by the modelling process. This process is guided by the question that originates the elaboration of the model and thus the definition of (1) indexes, in the form of the state of entities at the end of the simulation, a sampling of these states in the course of the simulation, or any expression calculated from these, susceptible to provide answers to the question and (2) scenarios enabling to test effects on indexes of different initial states or dynamics of interface or internal entities or even of different form of activities like farmer or dam manager strategies.

Regarding the construction of the model, this leads to identify on the one hand the entities that support the indexes and more generally the phenomena of interest and on the other hand the processes that influence the evolution of these entities. The model entities and processes are designed concurrently since an entity is relevant if and only if it is related to processes of interest and reciprocally. The progressive design of both 
the model and the question at hand is intimately and reflexively linked. Collective and progressive formalisation of Actors-Resources and Interaction Diagrams enables participants to the integrated modelling process to contribute to the design and share a common representation of the system. On other respects formal representation of dynamics of each process is the matter of each disciplinary team or even researcher. Each of them can choose the appropriate formal language to represent these dynamics according to their disciplinary and individual habits and specificities of the dynamics.

\subsection{The GAMA Simulation Platform}

The MAELIA simulation model is implemented with GAMA ${ }^{1}$ [15], an open-source generic agent-based modeling and simulation platform. It provides an intuitive modeling language with high-level primitives to define agents and their environment. GAMA includes a powerful Integrated Development Environment to ease noncomputer scientist to develop complex model with powerful features in terms of GIS integration and high-level tools (e.g. decision-making or clustering algorithms). In addition, both the language and the software have been designed to allow the development of big models with a huge number of agents (with various architectures from reflex-based to BDI architectures). It allows modelers to manage various kinds of complex environments such as square, hexagonal or irregular grids, networks or continuous environment linked to GIS data.

GAMA enables a hierarchical and dynamic organization of agents. Any agent is both a micro-agent (hosted in a macro-agent) and a macro one (hosting other agents). The platform is also easily extensible to add new features to models (e.g. to give the possibility to integrate equation-based (ODE) models into agents) or new agent architectures or features. GAMA has been successfully used to develop various largescale applications that share the need of a strong integration and management of huge GIS data and of strong interactions between complex environment and agents.

\section{The Model of the Integrated MAELIA Platform}

The MAELIA platform simulates the ecological processes and human activities underpinning water scarcity issues at the relevant spatial, temporal and functional resolutions. To model processes, the main strategy was twofold. For ecological processes, given that many models of water flow and plant/soil dynamics exist we selected models (i) robust that can be applied on the wide range of biophysical conditions of the AGB, (ii) empirically founded to be likely to provide realistic outputs (iii) with space and time resolutions fitting with our modeling needs on the AGB and (iv) quite simple in terms of number of equations and parameters to be not too time-consuming in calibration, coding and computing. For human activities, specific models were developed in order to represent the decision-making processes of the key users and managers of water resources. In this section we describe how firstly

\footnotetext{
${ }^{1}$ http://code.google.com/p/gama-platform/
} 
ecological processes and secondly human activities are considered and accordingly modeled within the MAELIA platform, without emphasizing the entities. Finally we present the way interactions between processes are managed in the platform.

\subsection{Ecological Processes}

To represent water flow we use the mathematical formalisms of hydrological cycle from the SWAT (Soil and Water Assessment Tool) model [6] because it quite well matches the requirements of the MAELIA project objectives as semi-empirical and semi-distributed model. The SWAT model has been applied in different watershed under contracted climatological and pedological conditions all over the world. SWAT has been developed to assess impact of land cover and use changes on water, sediments and agricultural yields. It is a semi distributed hydrological model in which the hydrological balance is estimated and spatially allocated into so called "sub-watersheds", i.e. elementary watersheds. These latter are subdivided into a spatial Hydrologic Response Units (HRUs) representing a unique combination of land cover, soil type and slope. The division into sub-watersheds allows the model to reflect the spatial organization of the hydrological network and reservoirs from where water is withdrawn. The subdivision into HRU is adapted to represent differences in evapotranspiration for various plants and soils and in runoff, infiltration and subsurface water circulation. The possibility to define the size of sub-watersheds allows adapting the model to match requirements of the investigated agro-hydrological issues. This modeling approach avoids using a distributed hydrologic model often much more complicated and computing-time consuming. SWAT simulates agro-hydrologic cycle with a daily time step at least. In MAELIA we analyze, document and recode equations of SWAT for both (i) the land phase of the hydrologic cycle that controls the amount of water loadings to the main channel of each sub-watersheds (snow cover and melt, runoff with the curve number method, infiltration, redistribution in soil profile, evapotranspiration for non-crop plants, lateral sub-surface flow and percolation into shallow and deep aquifer) and (ii) the routing phase of the hydrologic cycle that controls the flow of water through the channel network of the watershed toward the outlet (transmission through the bed of the channel in and from runoff, sub-surface flow and shallow aquifer, evaporation and water routing through the channel with the Muskingum routing method [2]). The sub-watershed and HRU delineation has been made thanks to a GIS approach based on French georeferenced databases on water resources, topography and land use. The average size of the MAELIA sub-watersheds is about 2 to $6 \mathrm{~km}^{2}$. It corresponds to the finest grain of the French watershed classification that is used to design and implement management strategies and policies.

To represent plant growth (and yield) we chose two strategies according the nature of plant. For non-crop plants (forest and grassland) we used the formalism of SWAT with the standard parameter values since MAELIA does not need to simulate biomass production. For crops we gave the priority to the capacity of the crop model to simulate realistic crop yields in the different situations of the ABG without great and often problematic calibration work. Accordingly we implement an empiric (vs. mechanistic) crop model developed by INRA (French national institute for 
agricultural research) in Toulouse (centre of the AGB). This model called "Jeu d'O" [7] has been developed step by step according results of agronomic experiments in the AGB during the last 20 years. It seeks to represent phenomena rather than mechanisms to ensure simplicity and robustness and accordingly large regional applicability. It represents effect of climate, soil and cropping system on yield for the eleven main crops of the AGB. The effect of water stress on yield is represented through an annual production function representing the relation between the coverage of crop water needs (ratio real to potential evapotranspiration) and effect on yield (ratio real to potential yield). This crop model simulates runoff given the effect of the crop above ground biomass development. It also represents effect on water soil dynamics of tillage (modification of soil layer depth that evaporates), sowing date (modification of the vegetation period) and irrigation.

The plant growth process simulates drainage and runoff of each sub-watershed fields and accordingly impacts shallow aquifer and river water states. This process interacts with the land phase of the hydrologic processes through this two water body types. Hence, as presented in Sect. 3, processes interact through entities.

\subsection{Socio-economic Process and Human Activities}

Since the MAELIA platform is intended to assess impacts of interactions between social and ecological processes, human activities and socio-economic processes need to be described. Socio-economics processes concern demography, land cover change and domestic and industrial water uses. Human activities concern farmer activities that determine their water withdrawals, management of dam water and implementation of water regulations that frames the fulfilment of the water demands.

Demography is treated as an external process using data provided by the French agency in charge of demography statistics.

In the AGB, urban and forest areas have been growing significantly during the last decades. In MAELIA, given the time horizon of the simulations (until 2030), we represent these land cover changes through the field plot disappearance ${ }^{2}$ : each year some field plots disappear in favour of forest or urban areas. For this, we first computed the number of disappeared plots from 2006 to 2010 in each sub-watershed thank to the Corine Land Cover database ${ }^{3}$ and second extrapolate the future yearly evolution until 2030. This time series is considered as an external process of the model (produced by a pre-treatment). Plots that disappear each year are randomly chosen next to urban or forest area (following the observed ratio).

The domestic water use is computed using the econometric equation developed in the MOGIRE model [12]. It takes the water price, the rate of houses that are used as main home, income, summer maximum temperature (external time series) and population density (provided by the demography process) as parameters. Three quarters of

\footnotetext{
${ }^{2}$ The most important cause of land use change related to our field of investigation is the field plot disappearance, evaluated to one French department par 10 years in France.

${ }^{3}$ Corine Land Cover France website: http://sd1878-2.sivit.org/ (as of 26/03/2012).
} 
the yearly withdrawn volume for domestic use is rejected (it returns to the river). From this volume, we compute the daily withdrawn and rejected volumes in each withdrawn and rejection points, taking into account that daily withdrawn volume are higher during summer. The industrial water use is an external process based on withdrawal and rejection data for year 2010 from the dedicated database of the AGB water agency, which considers that the volume remains constant over years.

As irrigation is the most important process regarding management of low water periods, we developed a precise model for farmer activities that underpin their water withdrawals. The behaviour of the farmer agent is composed of two processes with different time scales. Yearly, the farmer makes cropping plan decisions: he gets a complete allocation of crop rotations to his fields. The choice of a rotation is carried out through a multi-criteria decision-making process based on Dempster-Shafer belief theory included in a BDI architecture [14]. This theory allows to make a decision even with incompleteness, uncertainty and imprecision of knowledge. From surveys, the four following criteria have been accounted: maximize the profit and the similarity to the last cropping plan and minimize financial risks and workload.

The farmer then applies the schedule of each cropping system through daily activities that are enabled by the state of soils and crops: sowing, irrigation and harvesting. He takes into account the workload (aggregation of the farm manpower) constraint. Each daily activity has a temporal window during which it can be done and a set of conditions (e.g. in terms of weather) that should be fulfilled. The activities performance is limited by the number of hours the farm manpower can work and by geographical constraints (distance between fields, field surfaces...). In addition, if the sowing activity is not possible, e.g. because of strong rains, the farmer will re-evaluate the cropping plan to find an alternative one. The model includes only one farmer actor per farm: he will take all the decisions and performs the activities for the sake of all the farm manpower. In addition, he uses a lot of cognitive resources: technical (possible crop rotations), economic (markets) and social (decrees). The instantiation of entities is based on the French Land Parcel Identification System that describes the spatial distribution of plots (including one or a small numbers of fields) of each French individual farm.

In the $\mathrm{AGB}$, the strategy regarding releases of water stored in dams and regulations of agricultural water withdrawals during the low-water period determines to what extent both the compulsory water flow rates can be maintained and the agricultural needs can be satisfied (since the other needs have priority). This management is the result of complex multi-level regulatory and governance systems that extends from the European level to elementary watersheds where concrete actions dealing with water bodies take place. The MAELIA platform only includes the elements of the regulatory system that are involved in the concrete exercise of water management during low water periods. Elements that contribute to the emergence and deployment of the regulatory system itself are not represented. Accordingly we represent the activities of State services and commissioned associations regarding the management of water of dams and the setting of regulations of agricultural withdrawals.

Each year, a specified volume of water is purchased by State services to water reservoir managers that shall be preserved for release on demand in case of need. 
During low-water periods, the flow rate of streams and rivers is daily measured (as Average Daily Flow, ADF) at so-called monitoring points. Four thresholds are associated with each monitoring point, from Objective Low-Water Flow (OLWF) to Crisis Flow, to evaluate the ecological state. Measures or visual checks are also taken at other given locations along the hydrological network. State services manage water uses and resources according to these daily measures.

In priority, when possible, they try to maintain water flow objective thanks to water releases from dams. In rivers that can be replenished by some dams, they try to compensate agricultural withdrawals when the flow rate passes under the OLWF. Accordingly, the MAELIA State service actor seeks to optimise releases according to these objectives and the dam constraints: reserved flow (minimum water flow at the exit of the dam), maximum flow due to dam and river characteristics, period of release (e.g. to maintain the water level of the lake high enough for touristic activities), transfer time between the dam and the targeted monitoring points, emptying curve of the reservoir (that indicates, given the date and the remaining amount of water, the probability to be able to satisfy the needs of release until the end of the low water period). Due to the transfer time of water between dams and associated monitoring points, water withdrawals have to be anticipated. However as information on irrigated area for the current year and farmer irrigation strategies for the time is lacking he has to estimate agricultural water needs day after day. For this he uses local references on irrigated crop areas and needs. Dam characteristics and these local references are cognitive resources for the actor. They enable to estimate the water flow needed to respect the compulsory flow at the monitoring points day after day.

When it is not possible to sustain water flow through water releases (no dams in an upstream watershed, no more available water in the dam) the State services might issue Drought Decrees that state withdrawal restrictions in some place and for some duration: 1 or 2 days a week (level 1), 3 or 4 days a week (level 2) or 7 days a week (level 3). The condition for the promulgation of a drought decree and its pattern (locations, durations and levels) are framed by a generic drought decree and several official planning documents. This is a daily process during the low-water period. A decree applies to one or several areas. Each area is linked to a downstream monitoring point and is divided in sectors determining, for the decrees of level 1 or 2 , which days a prohibition applies. The level of restriction applicable to an area depends on the position of ADF3 (the average of ADF on the 3 last days) with regard to the thresholds of its monitoring point and the possibility to replenish the stream from an upstream reservoir. The decision to apply this restriction is constrained by principles regarding temporal continuity - an ongoing restriction cannot be upgraded before at least 3 days and downgraded before at least 7 days - and spatial solidarity - an upstream area must be a in restriction level greater or equal.

Farmers may be given a ticket for violation of drought decrees by certified civil servants. MAELIA implements the control of compliance and sanctioning in the following way: when drought decrees apply, each week hundred randomly chosen farmers are checked for the respect of restrictions. Infringements are just recorded, because the effective consequences of overtaking are still doubtful. The same holds for the annual quantity of abstracted water that should not overpass the granted quantity. 


\subsection{Interactions Between Processes Through Entities}

One of the main features of the MAELIA model is the fact that processes do not interact directly but only via resources. The best example in our model is the interactions between processes around the water resource at the watershed level. As presented above and summarized in Fig. 3, the sub-watershed is the key entity of the water flow model. It aggregates the water computed by the land phase and gets and provides water from upstream and to downstream watersheds through the routing phase. This water quantity computed at the sub-watershed level, is considered as a water reservoir in which various water users withdraw water for irrigation, consumption or industrial uses and reject water used for industry or for domestic consumption. In addition, withdrawals restrictions apply to sub-watershed water reservoirs.

As mentioned above, actors interact only via resources. For example, the prefect does not interact directly with farmers to prohibit irrigation, but via the creation of cognitive resources, that can be drought decrees and withdrawal restrictions.

\subsection{Running the Simulation Model}

The generation and the running of the simulation model require a lot of datasets, that supposes a (very) good empirical knowledge of the studied system.

Structural data are necessary to instantiate the model entities and relationships into a concrete model. This latter describes all the actual constitutive elements of the modelled system and serves as the initial state of simulations.

Dynamic data are temporal data series that describe dynamics of the state of the interface resources. Dynamic data are also needed for the calibration-validation of internal processes.

In the first version of the MAELIA platform, more than 250 structure and dynamics datasets are used. Most datasets require pre-processing to solve heterogeneity, compatibility and consistency issues and be put at the required temporal and spatial resolutions. Indeed, while there is a great number of data, most of them are collected in a specific context and purpose, without concern for a wider use ${ }^{4}$ and particularly an integrated modelling. Some of these pre-processing require expert knowledge to compensate the lack or incompleteness of data.

\section{Ongoing Work}

The current version of MAELIA implements all the presented processes on the Garonne upstream watershed $(125 \times 100 \mathrm{~km})$ using the GAMA platform. Figure 4 shows a synopsis of key results of a MAELIA simulation on the 2002-2008 period

\footnotetext{
${ }^{4}$ Within the French context, some incoming projects intend to solve these issues, which are also related to difficulties about the availability of data.
} 


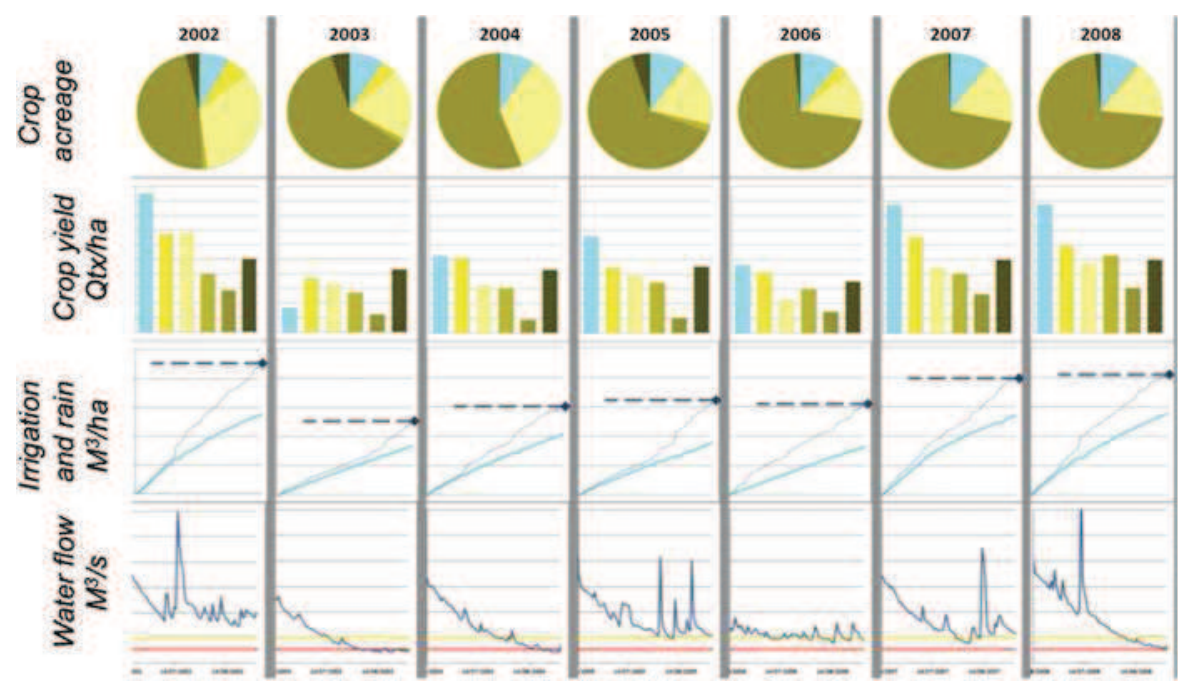

Fig. 4. Synopsis of keys results of a MAELIA simulation on the 2002-2008 period : crop acreage at the river basin level, crop yields for the main irrigated (blue $=$ corn) and rainfed crops (yellow to green : wheat, sunflower, pea, rapseed...), average cumulated water irrigation and rain in irrigated crop fields, water flow at the outlet of the river basin (yellow and red lines represent compulsory Objective low-water flow and Crisis flow) (Color figure online).

(with a day step). It shows the evolution of (i) crop acreage at the river basin level, (ii) crop yield for the main crops (depending on the water stress level), (iii) average cumulated water irrigation and rain level in irrigated crop fields and (iv) water flow at the river basin outlet. When the river flow drops below the crisis flow (the red line) drought decrees prohibit irrigation. This leads to increase water stress of irrigated crops and in turn to the decrease of crop yields. During the year 2003, the more intense drought over the fifteen last years, drought decrees and so prohibition of irrigation, and natural drought have strongly affected irrigated as well as rainfed crop yields.

Figure 5 shows a synopsis of the key processes simulated in the MAELIA platform at a given day: precipitation level (external process) in meteorological pixels, spatial position of farmers, in crop fields irrigation level in irrigated fields, crop growth stage in crop fields, rotation in crop fields, irrigation restriction level (due to drought decrees) in restriction zones, water flow at the outlet of each sub-watershed and air temperature (external process) in meteorological pixels.

We are currently working on calibration and evaluation of each process. Some processes can be validated in isolation, for example the farmers' cropping plan decision-making process (it gives very good results much better than other existing models [14]). One of the main issues regarding calibration stems from the reciprocal dependence between processes. For example, to calibrate hydrologic models, we only have observed data of water flow that take into account all the field processes impacting the water flow (weather, irrigation and other withdrawals, releases, regulations, etc.). We thus should rely on computed "natural" flow to calibrate separately the hydrologic model. 


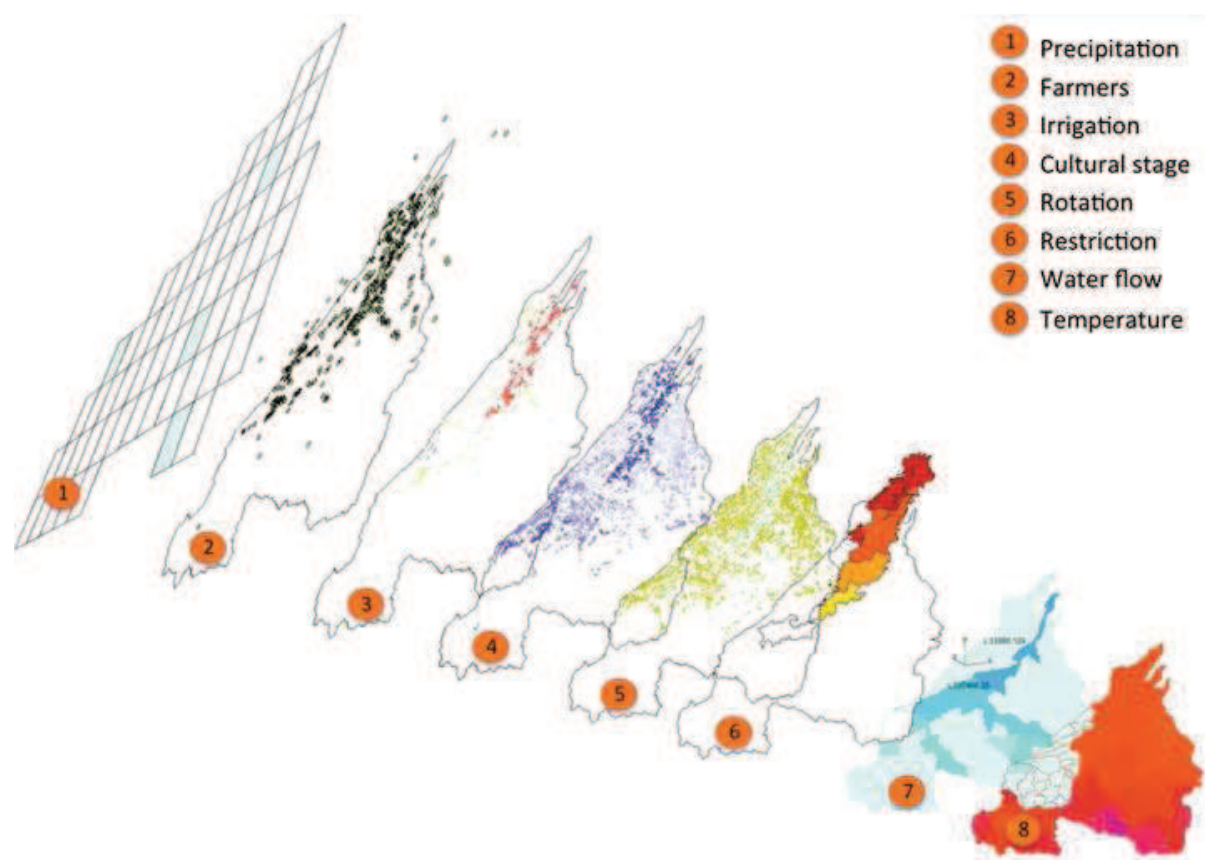

Fig. 5. Synopsis of the main processes simulated in the MAELIA platform (at a given day): precipitation level in meteorological pixels, spatial position of farmers, in crop fields irrigation level in irrigated fields, crop growth stage in crop fields, rotation in crop fields, irrigation restriction level in restriction zones, water flow at the outlet of each sub-watershed and air temperature in meteorological pixels

Acknowledgement. The MAELIA Project "Multi-Agents for EnvironmentaL norm Impact Assessment" (http://maelia1.wordpress.com/) is funded by the French "Sciences \& Technologies for Aeronautics and Space" Foundation (http://www.fondationstae.net/).

\section{References}

1. Bousquet, F., Page, C.L.: Multi-agent simulations and ecosystem management: a review. Ecol. Model. 176, 313-332 (2004)

2. Chow, V.T., Maidment, D.R., Mays, L.W.: Applied Hydrology. Tata McGraw-Hill Education, New York (1988)

3. Debril, T., Therond, O.: Les difficultés associées à la gestion quantitative de l'eau et à la mise en oeuvre de la réforme des volumes prélevables : le cas du bassin Adour-Garonne. Agronomie, Environnement \& Sociétés 2(10), 127-138 (2012)

4. Leenhardt, D., Therond, O., Cordier, M.-O., Gascuel-Odoux, C., Reynaud, A., Durand, P., Bergez, J.-E., Clavel, L., Masson, V., Moreau, P.: A generic framework for scenario exercises using models applied to water-resource management. Environ. Model Softw. 37, 125-133 (2012) 
5. March, H., Therond, O., Leenhardt, D.: Water futures: reviewing water-scenario analyses through an original interpretative framework. Ecol. Econ. 82, 126-137 (2012)

6. Arnold, J.G., Srinivasan, R., Muttiah, R.S., Williams, J.R.: Large area hydrologic modeling and assessment. I. Model development. J. Am. Water Resour. Assoc. 34(1), 73-89 (1998)

7. Nolot, J., Debaeke, P.: Principes et outils de conception, conduite et évaluation de systèmes de culture. Cah. Agric. 12, 387-400 (2003)

8. Ostrom, E.: A general framework for analyzing sustainability of social-ecological systems. Science 325, 419-422 (2009)

9. Pahl-Wostl, C., Schlumpf, C., Büssenschütt, M., Schönborn, A., Burse, J.: Models at the interface between science and society: impacts and options. Integr. Assess. 1, 267-280 (2000)

10. Parker, P., Letcher, R., Jakeman, A., Beck, M., Harris, G., et al.: Progress in integrated assessment and modelling. Environ. Model Softw. 17(3), 209-217 (2002)

11. Parrot, L.: Hybrid modelling of complex ecological systems for decision support: Recent success and future perspectives. Ecol. Inform. 6(1), 44-49 (2011)

12. Reynaud, A., Leenhardt, D.: Mogire: a model for integrated water management. In: International Environmental Modelling and Software Society (iEMSs), Barcelona, Spain (2008)

13. Sibertin-Blanc, C., Thérond, O., Monteil, C., Mazzega, P.: Formal modeling of socialecological systems. In: European Social Simulation Association Conference, Cemagref (2011)

14. Taillandier, P., Therond, O., Gaudou, B.: A new BDI agent architecture based on the belief theory. Application to the modelling of cropping plan decision-making. In: International Environmental Modelling and Software Society (iEMSs), Leipzig, Germany, pp. 1-5 (2012)

15. Taillandier, P., Vo, D.-A., Amouroux, E., Drogoul, A.: GAMA: a simulation platform that integrates geographical information data, agent-based modeling and multi-scale control. In: Desai, N., Liu, A., Winikoff, M. (eds.) PRIMA 2010. LNCS, vol. 7057, pp. 242-258. Springer, Heidelberg (2012)

16. Therond, O., Belhouchette, H., Janssen, S., et al.: Methodology to translate policy assessment problems into scenarios: the example of the seamless integrated framework. Environ. Sci. Policy 12(5), 619-630 (2009) 